\title{
Aerosol-fog interaction and the transition to well-mixed radiation fog
}

\author{
Ian Boutle $^{1}$, Jeremy Price ${ }^{1}$, Innocent Kudzotsa ${ }^{2}$, Harri Kokkola ${ }^{2}$, and Sami Romakkaniemi ${ }^{2}$ \\ ${ }^{1}$ Met Office, Exeter, UK \\ ${ }^{2}$ Atmospheric Research Centre of Eastern Finland, Finnish Meteorological Institute, Kuopio, Finland
}

Correspondence: Ian Boutle (ian.boutle@metoffice.gov.uk)

Received: 16 August 2017 - Discussion started: 13 October 2017

Revised: 4 May 2018 - Accepted: 17 May 2018 - Published: 4 June 2018

\begin{abstract}
We analyse the development of a radiation fog event and its gradual transition from optically thin fog in a stable boundary layer to well-mixed optically thick fog. A comparison of observations and a detailed large-eddy simulation demonstrate that aerosol growth and activation is the key process in determining the onset of adiabatic fog. Weak turbulence and low supersaturations lead to the growth of aerosol particles which can significantly affect the visibility but do not significantly interact with the long-wave radiation, allowing the atmosphere to remain stable. Only when a substantial fraction of the aerosol activates into cloud droplets can the fog interact with the radiation, becoming optically thick and well mixed. Modifications to the parameterisation of cloud droplet numbers in fog, resulting in lower and more realistic concentrations, are shown to give significant improvements to an NWP model, which initially struggled to accurately simulate the transition. Finally, the consequences of this work for common aerosol activation parameterisations used in climate models are discussed, demonstrating that many schemes are reliant on an artificial minimum value when activating aerosol in fog, and adjustment of this minimum can significantly affect the sensitivity of the climate system to aerosol radiative forcing.
\end{abstract}

\section{Introduction}

Radiation fog is a challenging problem for numerical weather prediction (NWP) models. To obtain an accurate forecast, models must correctly represent the coupling between the land surface and atmosphere, which leads to fog formation, and the coupling between different atmospheric parameter- isations (cloud microphysics, turbulence, radiation), which determine the evolution of the fog. It is therefore unsurprising that the quality of NWP fog forecasts remains low. Significant advancement in both the physical process understanding and modelling is required to achieve forecasts of similar quality to those produced for other high-impact weather events.

Several recent studies have focussed on large-eddy simulation (LES) of foggy events (Bergot et al., 2015; Mazoyer et al., 2017; Maronga and Bosveld, 2017) to investigate the systematic response of fog to various dynamical and physical processes. All of these studies showed how quantities such as wind speed, temperature, humidity or land-surface characteristics, influence the initiation, peak intensity and dissipation of fog, often in a fairly linear way. However, Price (2011) showed that fog can undergo more significant bifurcations in its behaviour. He showed that, for a site in south-eastern England, approximately $50 \%$ of fog events remained as optically thin condensed water in a stable boundary layer, whilst the other $50 \%$ formed optically thick (i.e. zero net surface radiation), well-mixed, adiabatic fog, with the turbulence generated by radiative cooling giving the fog a distinct structure of its own. Identifying this transition, and more importantly, being able to forecast what causes it would be of significant value. Stable fog generally persists throughout the night-time, dissipating quickly due to solar heating in the morning. However, adiabatic fog has the ability to persist for days, greatly increasing its potential to cause disruption to infrastructure such as road traffic and airports.

One possible mechanism for this non-linear response could arise from atmospheric aerosol concentrations and their interaction with the developing fog layer. Bott (1991) 
thoroughly studied the effect of aerosol concentrations and properties on single-column model simulations of the life cycle of radiation fog. He demonstrated that, as aerosol concentrations were increased, the fog became deeper, with higher condensed water content, and was less likely to be dissipated by solar radiation. Despite the crucial importance of this conclusion for NWP forecasts, most operational models used for fog prediction do not consider variable aerosol or fog droplet number concentrations (e.g. Gultepe et al., 2006; Tudor, 2010; van der Velde et al., 2010), and therefore it may be unsurprising that they struggle to obtain sufficient accuracy.

The Local and Non-local Fog Experiment (LANFEX, Price et al., 2018) was a recent UK attempt to gather new observations of foggy events to make significant progress in their understanding and modelling. This paper focusses on the first intensive observation period (IOP1), during which a shallow, optically thin fog transitioned slowly into a wellmixed, optically thick fog. This paper aims to extend the work of Bott (1991), investigating the role aerosol plays in this transition and establishing whether an NWP model is capable of reproducing the observed behaviour. We discuss the current ability of an NWP model to reproduce the observations (Sect. 3), investigate the mechanisms causing the transition (supplementing the observational analysis with process modelling from an LES; Sect. 4) and evaluate some simple improvements to the NWP model (Sect. 5). As we find that one of the key processes is the representation of aerosol activation within the model, we conclude (Sect. 6) with some interesting consequences of this work for the climate system and climate modelling.

\section{Case and model details}

IOP1 took place on the night of 24-25 November 2014 and was measured at the Met Office field site at Cardington, UK $\left(52.1015^{\circ} \mathrm{N}, 0.4159^{\circ} \mathrm{W}\right)$. Widespread radiation fog formed across much of the country and remained stable for much of the night before becoming adiabatic later. IOP1 was one of the cleanest examples of local fog development observed during LANFEX, with no evidence that advective or non-local processes were significant (this has been tested in single-column model simulations with and without advective forcing; not shown). A detailed set of research-grade observations are available from the Cardington site, including a $50 \mathrm{~m}$ flux tower, radiosonde launches, a cloud droplet probe flown on a tethered balloon and standard surface and subsurface measurements (see Price et al., 2018, for more details).

The NWP model considered in this paper is the Met Office Unified Model, specifically the $1.5 \mathrm{~km}$ horizontal grid-length UKV model. Details of this model and some discussion of its ability to forecast fog can be found in Boutle et al. (2016), although several aspects of the model dynamics (Wood et al., 2014), turbulence (Boutle et al., 2014b) and cloud micro- physics (Boutle et al., 2014a) parameterisations have been significantly upgraded. For the simulations presented, the model is initialised from its own analysis at 12:00 UTC on 24 November 2014 and is free-running after this, forced only at the boundaries by data from the Met Office global model (Walters et al., 2017b). The model contains 70 vertical levels, 6 of which are below $150 \mathrm{~m}$ and the lowest of which are at $2.5 \mathrm{~m}$ for horizontal winds and $5 \mathrm{~m}$ for temperature and humidity. As discussed in Clark et al. (2008), the model contains a single-species prognostic aerosol, which is used in the diagnosis of near-surface visibility, and converted to cloud droplet number (Wilkinson et al., 2013; Osborne et al., 2014) for use in the radiation and microphysical parameterisations, i.e. the first and second indirect effects.

To understand the physical processes leading to the observed behaviour, we also consider simulations using UCLALES-SALSA (Tonttila et al., 2017) as a process model. This model comprises an LES model coupled to a detailed, interactive, aerosol-cloud microphysics model and has been used previously to investigate the role aerosols play in the development of radiation fog (Maalick et al., 2016). Within the LES model, aerosol is partitioned into 10 bins covering the size range $3 \mathrm{~nm}$ to $10 \mu \mathrm{m}$. Water condensation onto aerosol particles is calculated by numerically solving the condensation equation at every time step and grid point. Thus we are able to explicitly simulate how radiative cooling and turbulence affect the water saturation ratio and how this affects the size of the aerosol particles. If aerosol becomes activated (i.e. its size exceeds the critical size given by Köhler theory), it is transferred into a separate sectional cloud droplet model, with bin sizes matching those of the dry cloud condensation nuclei and diagnosed wet sizes, typically between 0.7 and $50 \mu \mathrm{m}$. Thus we do not employ any traditional parameterisation of activation commonly used in other models but instead simulate the actual supersaturation and growth of aerosol particles into droplets. Comparisons with a more detailed parcel model (Kokkola et al., 2008) demonstrate that this growth is solved with good accuracy for a range of air parcels and updraught velocities.

For the simulations presented, the LES is initialised at 17:00 UTC with a radiosonde profile and forced at the surface throughout the simulation with the observed surface temperatures. This ensures that the simulation remains close to the observations throughout, avoiding the large uncertainties in the land-surface model discussed by Maronga and Bosveld (2017). In this case, the surface fluxes are very small and typically negative; therefore feedbacks from the land to atmosphere are not expected to play a great role (although this will not always be the case, particularly when fluxes are larger and positive). The domain size is $500 \times 500 \mathrm{~m}$ in the horizontal with a $4 \mathrm{~m}$ grid-length and $700 \mathrm{~m}$ in the vertical with a $1.5 \mathrm{~m}$ grid-length below $150 \mathrm{~m}$, above which a stretching factor of 1.05 is applied. The time step is variable but is typically around $0.25 \mathrm{~s}$ after the turbulence has formed. As such, the cloud activation within turbulent updraughts is 
well resolved, occurring on the timescale of a few seconds. The aerosol distribution was initialised with $1000 \mathrm{~cm}^{-3}$ number concentration of Aitken-mode aerosols (mean diameter $0.05 \mu \mathrm{m}$ ), $100 \mathrm{~cm}^{-3}$ accumulation-mode aerosols (mean diameter $0.15 \mu \mathrm{m}$ ) and $2 \mathrm{~cm}^{-3}$ coarse-mode aerosols (mean diameter $1 \mu \mathrm{m}$ ), each following a log-normal distribution with standard deviation of 2. Sadly, direct observations of aerosol concentrations were not available for this case, but this distribution is representative of the clean air typically found at Cardington. Several different aerosol concentrations were tested and we briefly discuss the sensitivity to this choice in the conclusions. During the simulations, water condensation on cloud droplets is explicitly calculated, and collision processes between differently sized hydrometeors are also accounted for. Because radiation fog is relatively thin, and there is no real precipitation formation, the autoconversion is turned off in the model. Instead, hydrated aerosol particles and cloud droplets are allowed to sediment onto the surface. Full details can be found in Tonttila et al. (2017) and references within.

\section{NWP model simulations}

The observations (Fig. 1a) showed a drop in visibility to $\approx$ $1 \mathrm{~km}$ as haze and patchy fog formed just before 18:00 UTC, followed by the continuous onset of thicker fog just after 20:00 UTC as the visibility dropped to near $100 \mathrm{~m}$. The fog persisted for approximately $12 \mathrm{~h}$ throughout the night, clearing at around 08:00 UTC the following morning.

The control UKV shows a very good simulation of the pre-fog conditions, tracing the observed surface temperature (Fig. 1b) almost perfectly until the onset of fog at 20:00 UTC. The model then shows a sharp drop in median visibility, down to $<100 \mathrm{~m}$, at approximately the same time that the observations show a drop in visibility to similar values. The model also produced non-zero probabilities of visibility < $1 \mathrm{~km}$ from 18:00 UTC; therefore it appears that the onset of fog, particularly the timing, is reasonably well reproduced in this model. However, after the onset of fog, there are noticeable differences between the model and observations. The model shows a $2 \mathrm{~K}$ increase in surface temperature immediately after the onset of fog, something which is not apparent in reality. It also appears that the fog is too thick in the model, with visibilities close to $60 \mathrm{~m}$, compared with $200 \mathrm{~m}$ in the observations. The dissipation of fog also occurs about $1-1.5 \mathrm{~h}$ too early, although this is due to a bank of mid-level cloud arriving at the location too early in the model. The cloud causes an increase in downwelling long-wave radiation, which directly heats the surface and fog layer, causing its dissipation. In reality, it is difficult to determine whether it was the presence of this cloud or the onset of downwelling short-wave radiation after sunrise (08:00 UTC) which caused dissipation, as both occurred at approximately the same time.
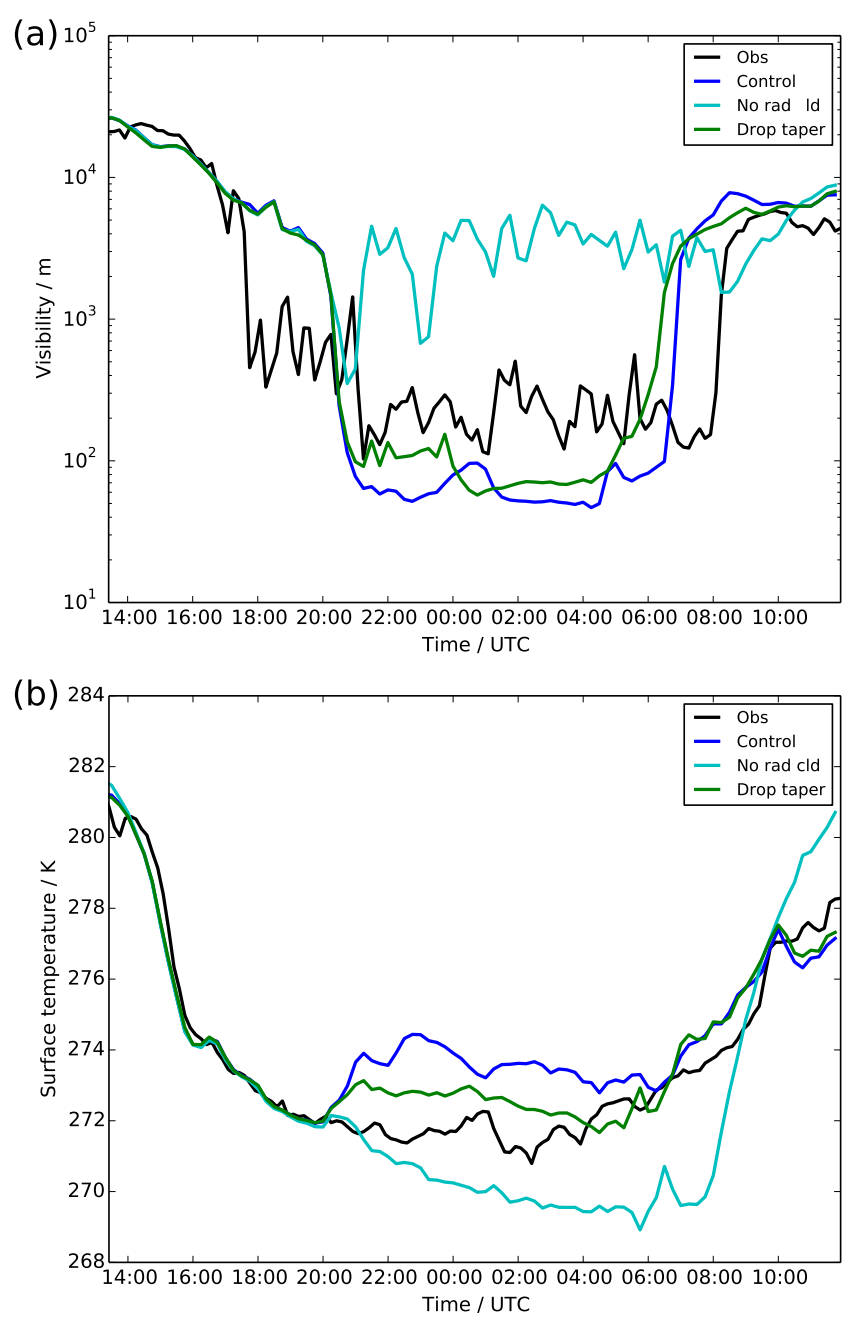

Figure 1. Time series of observations (black) and UKV experiments: control (blue), radiatively inactive cloud (cyan) and modified droplet number (green), showing (a) visibility and (b) grass-surface temperature.

Figure 2 shows the screen temperature and surface sensible heat flux from the UKV simulation. The sharp rise in surface temperature after the onset of fog leads to a positive sensible heat flux being formed throughout the night. Although modest in size $\left(10 \mathrm{~W} \mathrm{~m}^{-2}\right)$, it is in clear contrast to the observations which remain near zero throughout, and drives a warming of the screen temperature, which therefore remains warmer than the observations. Figure 3 shows the effect this has throughout the boundary layer. The positive heat flux exists through the lowest $50 \mathrm{~m}$ of the atmosphere before dropping to zero at what is likely to be the boundary layer top. The observations, by contrast, show a near-zero flux throughout the depth of the boundary layer. The consequence of this for the temperature profiles is that reality maintains a stable boundary layer, whilst the model has a well-mixed temperature profile indicative of an unstable boundary layer. 

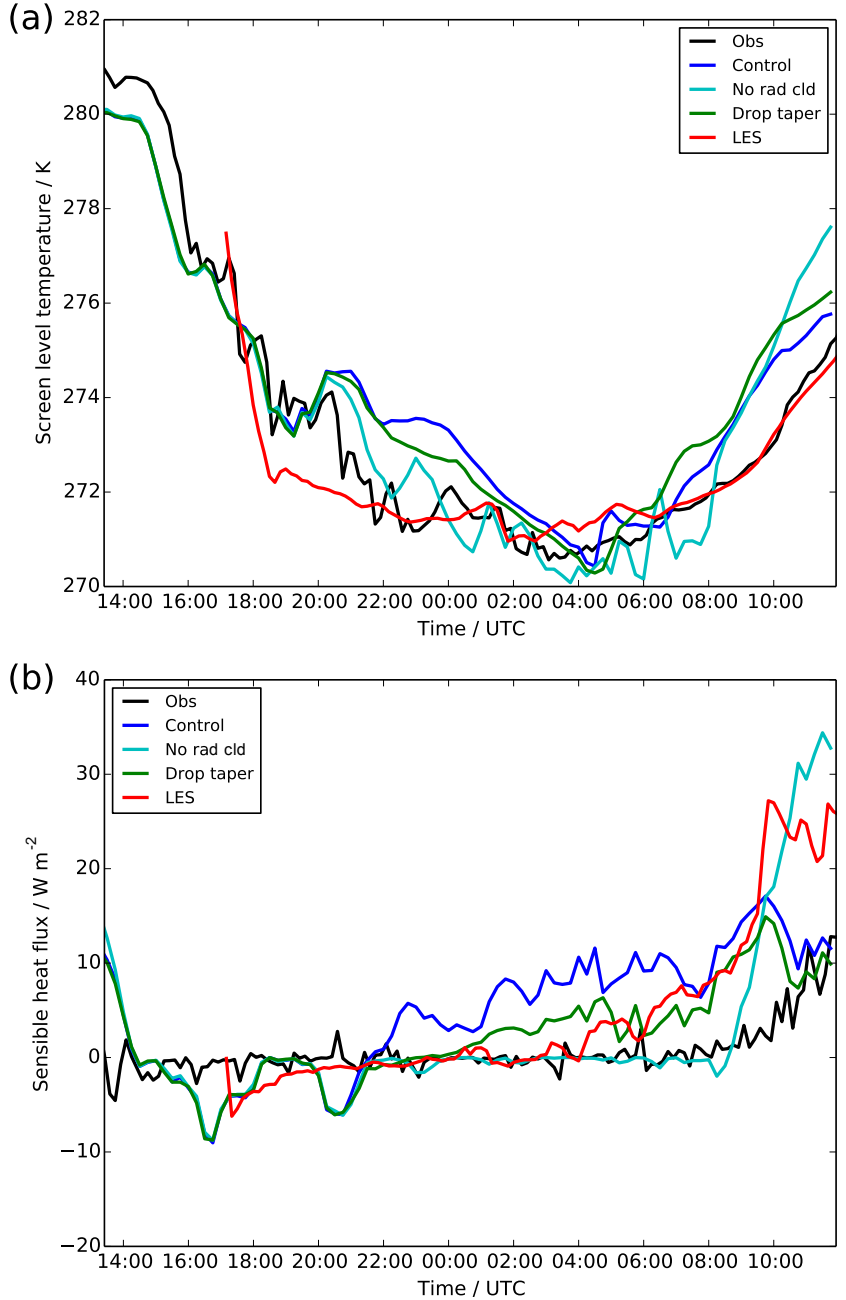

Figure 2. Time series of observations (black), LES (red) and UKV experiments: control (blue), radiatively inactive cloud (cyan) and modified droplet number (green), showing (a) screen $(1.5 \mathrm{~m})$ temperature and (b) surface sensible heat flux.

To understand what is going wrong in the model, it is useful to consider the typical evolution of a real-world radiation fog event, such as this one. Long-wave radiative cooling of the land surface gives rise to a stable boundary layer profile, and a thin fog will form within this profile when the relative humidity reaches $100 \%$. Initially this fog will only interact weakly with the environment, allowing the surface and air temperature to continue to cool and the fog to thicken. It will take several hours for the fog to start to develop turbulent behaviour of its own. At this point, long-wave radiative cooling from the fog top will generate negatively buoyant air parcels, which will descend throughout the fog layer and generate turbulence. Long-wave emission from the fog layer will also act to heat the surface, which is now "insulated" from the clear sky by the fog layer, and this in turn will maintain its temperature or even allow it to warm, generating a positive surface sensible heat flux. Upward heat flux from the soil is also
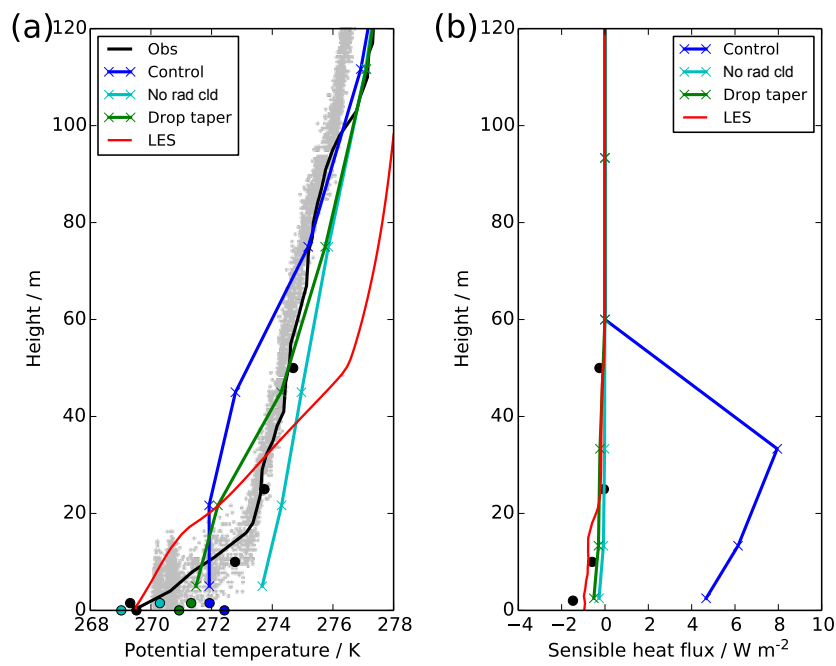

Figure 3. Profiles at 22:30 UTC showing observations (mast: black circles, radiosonde: black line, tethered balloon: grey dots), LES (red) and UKV experiments: control (blue), radiatively inactive cloud (cyan) and modified droplet number (green), showing (a) potential temperature and (b) sensible heat flux. Model profiles show model-level data (crosses) and diagnosed screen and surface-level temperature (filled circles).

a significant contributor to surface heating once the surface net radiation has reached near zero (Duynkerke, 1999). The combination of these processes is what leads to the development of a well-mixed fog layer, but this process normally takes many hours. However, the model appears to be simulating this process almost instantaneously - mature, well-mixed fog is formed within an hour of fog onset.

The radiative effect of the fog appears to be a key feature in the process; therefore as a sensitivity test we turn off the radiative effect of any fog which forms in the model (i.e. by setting the absorption and scattering coefficients for condensed water to zero, denoted "No Rad Cld"), shown in Figs. 1-3. The screen temperature and sensible heat flux now show a very good agreement with observations, although the surface temperature is now far too cold and no appreciable fog layer actually forms; i.e. the visibility remains quite high. This demonstrates that the radiative feedback is very important in both the development of the fog and in maintaining the surface temperature. Although fog does form due to the temperature dropping and relative humidity reaching $100 \%$, the lack of any enhanced radiative cooling from the fog itself prevents further development and thickening of the fog. There are also differences in the temperature structure between the model and observations. The layer of enhanced cooling near the surface is $\approx 20 \mathrm{~m}$ deep in reality, whereas it sits entirely below the lowest model level in the model. This means that the gradient is much sharper, explaining the colder surface temperature for given (and approximately correct) free atmospheric temperatures and screen-level temper- 

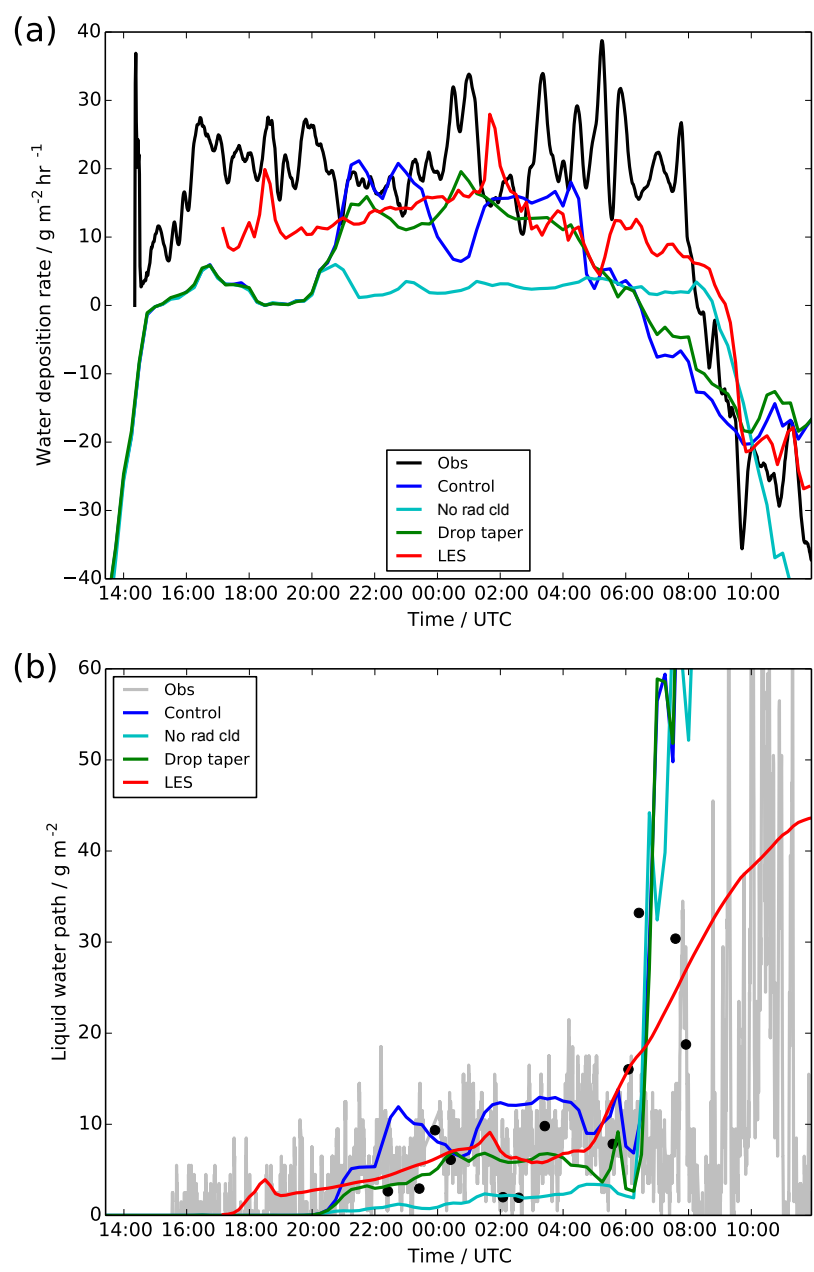

Figure 4. Time series of (a) surface water deposition rate, and (b) liquid water path, showing observations (a black; b tethered balloon: black dots, radiometer: grey line), LES (red) and UKV experiments: control (blue), radiatively inactive cloud (cyan) and modified droplet number (green).

ature. It is unclear whether this is a consequence of the fog interaction or the model vertical resolution, as discussed in Vosper et al. (2013).

Whilst having radiatively inactive fog is clearly unrealistic, the differences in temperature and heat-flux evolution from the control simulation suggests that perhaps the fog is too radiatively active. Guedalia and Bergot (1994) showed that errors in the development of radiation fog can be caused by errors in dew deposition - depositing too little dew onto the surface leaves too much condensed water in the atmosphere, which in turn has too strong a radiative effect. Figure $4 \mathrm{a}$ shows observations of dew deposition from the instrument described in Price and Clark (2014) in comparison to the model. During the main period analysed (20:00 to $04: 00$ UTC) the control simulation is in reasonable agreement with the observations - it is at the lower end of the observational range but certainly within the uncertainty of the instrument. Before 20:00 UTC, the control simulation underestimates the deposition, and this is likely to be due to hygroscopic absorption, a process not accounted for in the model's surface latent heat flux parameterisation, as discussed in Price and Clark (2014). There is also very shallow and inhomogeneous fog present in reality at this time, which is not simulated by the model, as it is only several metres deep and thus below the first model level, but it will contribute to the observed deposition rate. The radiatively inactive fog, by contrast, shows almost no deposition throughout the simulation, and this is due to the fact that no appreciable fog layer forms in the simulation, and the dominant (model) process leading to surface dew deposition is sedimentation of condensed water onto the surface.

Hence the dew deposition may be slightly underestimated in the control simulation, but the effect of this will only become significant if it, in turn, leads to a significant overestimate in the condensed water content. Figure $4 \mathrm{~b}$ shows the liquid water path (LWP) and Fig. 5a a profile through the fog layer from the tethered balloon. The profile shows the kind of variability which exists in the fog depth and water content and is not indicative of any fog development between the two observation times. The control simulation is in reasonable agreement with the observations for much of the night, although generally at the higher end of observed variability. The radiatively inactive fog is clearly too thin when compared to all available observations. Hence it appears that errors in dew deposition and the evolution of the condensed water content are not the main causes of error in the radiative effect of fog. However, the radiative effect of fog is not only controlled by the liquid water content but also by the number of cloud droplets and therefore their size. Figure 5b shows that the number of droplets observed from the tethered balloon is significantly lower than those predicted by the model.

The model parameterisation (Wilkinson et al., 2013) uses a fixed value of $75 \mathrm{~cm}^{-3}$ for the droplet concentration at the lowest model level, tapering up to a value determined by the concentration of aerosol (Osborne et al., 2014) at $150 \mathrm{~m}$. This tapering process is a pragmatic attempt at representing the fact that cloud droplet numbers in fog tend to be lower than those observed higher up in the atmosphere (Gultepe et al., 2009; Price, 2011). However, it appears that it is failing to represent some key features. The droplet numbers in fog are believed to be low because, despite the abundance of aerosol near the surface from which cloud droplets could form, the lack of any appreciable updraughts in the near-surface stable boundary layer results in weak supersaturations. This prevents the aerosol from being activated and therefore only relatively few aerosol droplets become hydrated. The observations also show the droplet numbers to be approximately constant throughout the fog layer, whilst the model's (imposed) profile increases quickly with height from its surface value, due to the large value diagnosed higher up from the aerosol concentration. 

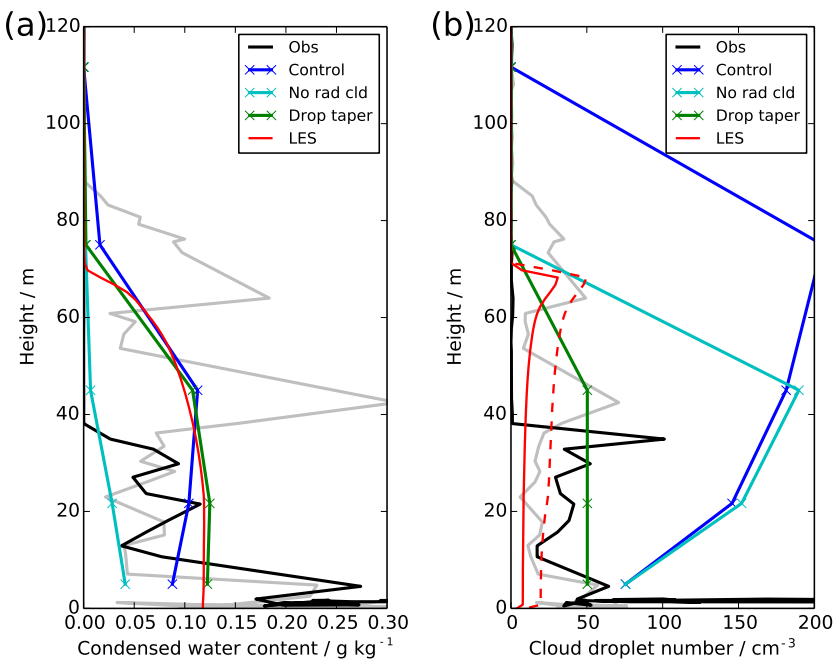

Figure 5. Profiles at 00:30 UTC showing observations (00:00 UTC: grey, 00:30 UTC: black), LES (red) and UKV experiments: control (blue), radiatively inactive cloud (cyan) and modified droplet number (green), showing (a) cloud liquid water content and (b) cloud droplet number concentration. For the LES droplet number, we show only the activated droplets (solid) and all particles $>2 \mu \mathrm{m}$ (dashed).

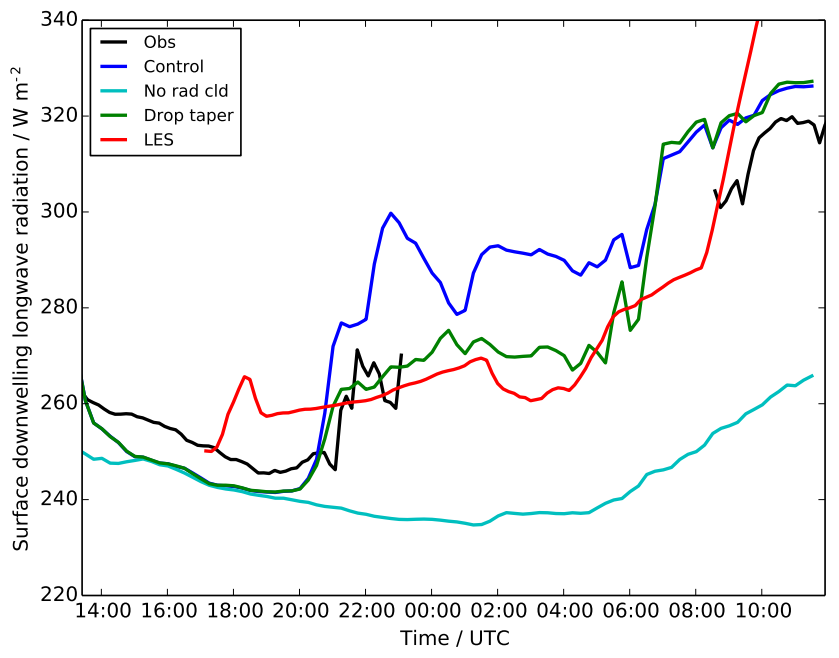

Figure 6. Time series of surface downwelling long-wave radiation, showing observations (black), LES (red) and UKV experiments: control (blue), radiatively inactive cloud (cyan) and modified droplet number (green).

The abundance of small cloud drops in the model will increase the cloud absorptivity, making the fog optically thicker and more radiatively important. This will drive stronger radiative cooling from the fog top, enhancing the turbulence and causing the development of well-mixed fog. It will also increase the downwelling long-wave radiation at the surface, which will in turn heat the surface and drive a

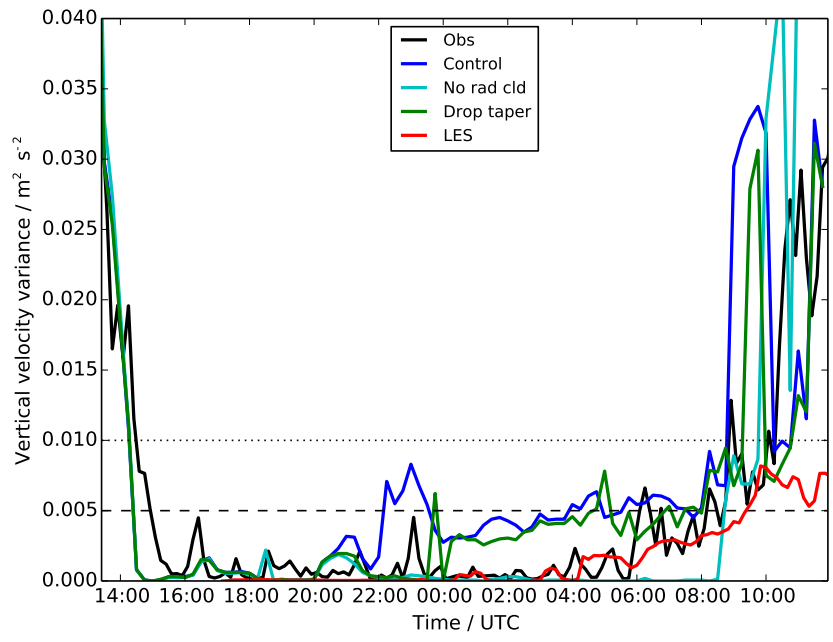

Figure 7. Time series of vertical velocity variance at screen level ( $2 \mathrm{~m}$ ), showing observations (black), LES (red) and UKV experiments: control (blue), radiatively inactive cloud (cyan) and modified droplet number (green). Also shown are the Price et al. (2018) value above which fog will not form (dashed) and the minimum value used in most activation parameterisations (dotted).

positive sensible heat flux. However, observations of downwelling long-wave radiation (Fig. 6) are not available for much of the night due to ice formation on the dome of the radiometer rendering the measurements unusable. The initial rise in downwelling long-wave radiation (between 20:30 and 23:00 UTC, before the ice formed) is representative of the fog, and it would not be unreasonable to assume that values remained near $270 \mathrm{~W} \mathrm{~m}^{-2}$ throughout the night, perhaps increasing slightly as the fog developed. Therefore the model would appear to have excessive downwelling long-wave radiation, but at this point we shall appeal to the additional information that can be provided by the LES model to support this conclusion.

\section{LES analysis}

Figures 2-6 also showed results from the LES, which generally appear to be in good agreement with the observations, demonstrating that the LES is a representative proxy for reality. They also confirm that the low cloud droplet number (Fig. 5b) is responsible for a much lower downwelling longwave radiation (Fig. 6) than is simulated by the UKV. The LES also provides the opportunity to explore the mechanisms leading to cloud droplet activation (or lack thereof) in the fog and therefore to suggest improvements to the NWP model.

Figure 7 shows the near-surface vertical velocity variance, which is very low in the observations and all models. Indeed it is safely below the $0.005 \mathrm{~m}^{2} \mathrm{~s}^{-2}$ suggested in Price et al. (2018) for the threshold value above which fog will not form. What this implies is that the peak updraught speed driving 

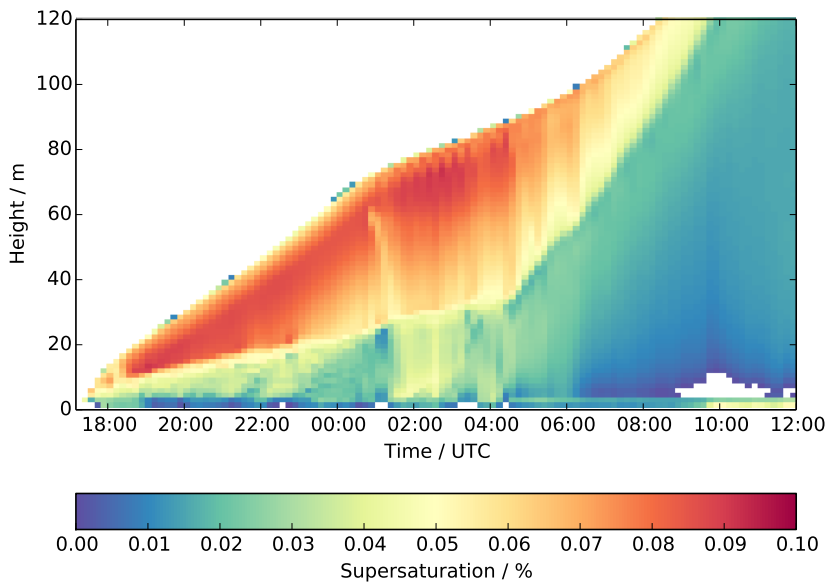

Figure 8. Time-height contour plot from the LES showing water vapour supersaturation with respect to the saturation vapour pressure over liquid water.

aerosol activation is very low, typically $<0.1 \mathrm{~ms}^{-1}$. This is much lower than the typical updraught speeds found in "normal" clouds (i.e. those which do not contain a rigid surface at their lower boundary). Because most models do not prognose or diagnose supersaturation, most aerosol activation parameterisations (e.g. Ghan et al., 1997; Morrison and Gettelman, 2008; West et al., 2014) link this updraught speed directly to the number of activated droplets. However, these parameterisations were not developed in the weak updraught regime of radiation fog, instead typically imposing a minimum updraught velocity or standard deviation of $0.1 \mathrm{~ms}^{-1}$ or higher. Therefore, if any schemes like this are used to simulate aerosol activation in fog, they will systematically overestimate the amount of aerosol activation and therefore the cloud droplet number, with inevitable consequences such as those discussed in Sect. 3.

For fog formation, updraughts are obviously not the only process that will activate aerosol and lead to the formation of cloud droplets. The fundamental process which drives activation is the ambient supersaturation, driven by adiabatic cooling, which can be driven by updraughts but in fog is also driven by direct cooling of the atmosphere. The observed cooling rate during the first few hours of fog formation (Fig. 2a) is $1 \mathrm{Kh}^{-1}$, which would be equivalent to an updraught speed of $0.04 \mathrm{~ms}^{-1}$ assuming a temperature lapse rate of $6.5 \mathrm{~K} \mathrm{~km}^{-1}$. This is still significantly below the $0.1 \mathrm{~ms}^{-1}$ minimum used for aerosol activation (even when added to the observed turbulent vertical velocities), demonstrating that typical parameterisations do not even indirectly represent the physical processes or amount of aerosol activation correctly. Further work is clearly warranted to develop schemes which are appropriate for this regime.

Figure 8 shows the supersaturation as predicted by the LES throughout the simulation. The first point to note is that the values are very low, $<0.1 \%$, which is much lower than val-
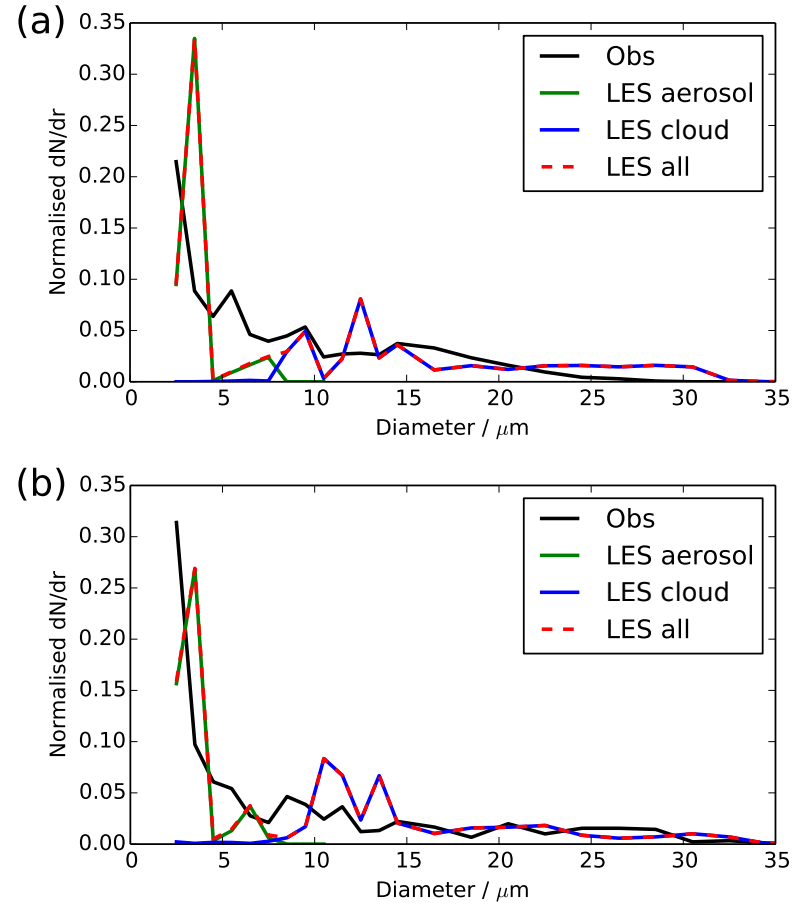

Figure 9. Cloud droplet size spectra at (a) 00:30 UTC and (b) 03:30 UTC, showing observations (black) and LES (red). For the LES, we also show the number of activated drops (blue) and number of aerosol particles (green).

ues typically found in clouds $(0.3-1 \%$, Ghan et al., 1997; $0.2-1.5 \%$, Spracklen et al., 2011). Low supersaturation values are also supported by earlier observations in different fog campaigns. For example, in the ParisFog campaign in France, the maximum effective supersaturation was found to be less than $0.05 \%$, with the average activation diameter of particles between 350 and $450 \mathrm{~nm}$ (Hammer et al., 2014). Similar findings were also obtained in the Po Valley, Italy, highlighting the role of aerosol chemical composition (Gilardoni et al., 2014).

These low supersaturation values explain the very low levels of aerosol activation and therefore low cloud droplet number values. Figure 9 shows the size spectra of particles $>2 \mu \mathrm{m}$, which shows that there are large numbers of very small particles $(<5 \mu \mathrm{m})$ in both the observations and LES. It is likely that these particles are not activated cloud drops, but large aerosol particles which have absorbed water and swollen in size. We note here that we have excluded the lowest $(1-2 \mu \mathrm{m})$ bin of the cloud droplet probe from our analysis to avoid potential noise issues with large, dry aerosol affecting the numbers. Because of the low supersaturation and therefore high activation diameter, hydrated aerosol particles within fog can grow larger than micrometre in size and can contribute up to $68 \%$ of total light scattering during different fog periods (Hammer et al., 2014; Elias et al., 2015). However, most of these hydrated particles are still too small to 
considerably affect interaction with long-wave radiation after fog has developed. This explains how the visibility can become so low, and yet the fog remains optically thin and the boundary layer stable.

The LES allows us to analyse this further, because we can break the size spectra into their contributions from hydrated particles which are still in the LES aerosol classes and particles which have been activated into the LES cloud droplet classes, i.e. exceeded the critical size given by Köhler theory. As shown in Fig. 9, almost all particles in the LES with diameter $<6 \mu \mathrm{m}$ are wet aerosol, and only those with diameter $>6 \mu \mathrm{m}$ are activated cloud drops. This distinction can also be seen in profiles of the cloud droplet number (Figs. 5b and 10b), where we have shown both the LES results for all particles $>2 \mu \mathrm{m}$ (as measured by the cloud droplet probe) and only those which are activated cloud drops. There is approximately a factor of 2 difference between these two estimates of cloud droplet number, with the all-particle estimate comparing best with the observations. In the simulation, aerosol is assumed to be composed of ammonium sulfate, which might be more hygroscopic than the actual aerosol observed during IOP1. Less hygroscopic aerosol would have a lower growth factor within fog, and thus the transition from hydrated aerosol to activated fog droplets would be seen at a smaller diameter. However, less hygroscopic aerosol would also activate less efficiently, thus increasing the critical dry diameter of activating particles. Thus we are confident that the small droplets seen in the observations are not fully activated but are significantly hydrated aerosol. This suggests that many observational estimates of fog droplet number, particularly in clean air masses, could actually be overestimating the number of activated droplets (i.e. those that are radiatively important in the long wave).

The supersaturation and turbulence levels remain remarkably constant throughout the night (up to 04:00 UTC), resulting in a cloud droplet number concentration which also remains reasonably constant throughout the night (Figs. 5b and 10b). This implies that the downwelling long-wave radiation (and optical depth) of the fog is mainly driven by its physical depth, which grows throughout the night (see Fig. 8). The growth of the fog layer leads to a gradual but continuous increase in the downwelling long-wave radiation throughout the night (Fig. 6), with the exception of a small decrease around 02:00 UTC. This occurs because of a sharp decrease in the background specific humidity (not shown) at around $80 \mathrm{~m}$, and therefore the fog growth is temporarily inhibited due to the entrainment of this drier air. This gradual rise in the downwelling long-wave radiation is responsible for the surface temperature ceasing to cool by 02:00 UTC and slowly warming throughout the rest of the night, which in turn drives a slow transition towards a well-mixed fog layer.

Figure 10 shows that by 03:30 UTC, the surface is warmer than the near surface and the lowest $20 \mathrm{~m}$ of the atmosphere is well mixed, with the top portion of the fog layer remaining stable. It is interesting to note that once the fog becomes adi-
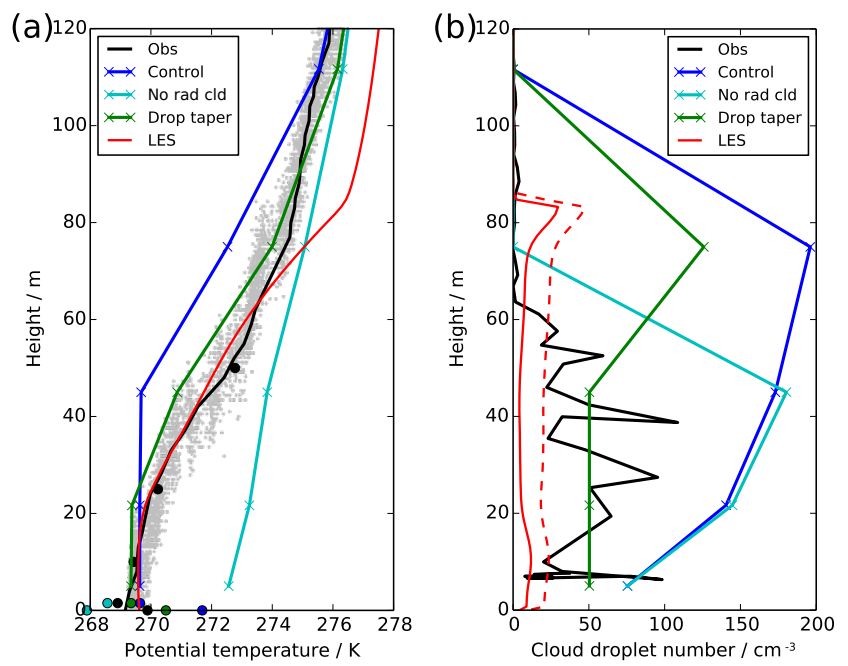

Figure 10. Profiles at 03:30 UTC showing observations, LES (red) and UKV experiments: control (blue), radiatively inactive cloud (cyan) and modified droplet number (green), showing (a) potential temperature and (b) cloud droplet number concentration. Model profiles show model-level data (crosses) and diagnosed screen and surface-level temperature (filled circles). For the LES droplet number, we show only the activated droplets (solid) and all particles > $2 \mu \mathrm{m}$ (dashed).

abatic, the mixed layer temperature is very similar to that predicted by the control NWP model, although the NWP model mixed layer is much deeper because it has been developing for many hours. This can also be seen by the convergence of screen temperature in all models around 04:00 UTC in Fig. 2a. After this time, the updraught speeds within the fog begin to grow, leading to increased droplet activation and a rise the observed and LES cloud droplet numbers. Figure $9 \mathrm{~b}$ shows a small secondary peak in the size spectra around $10 \mu \mathrm{m}$, developing due to the increasing turbulence, and the evolution of the spectra and cloud droplet numbers after this point is very similar to that already reported in Price (2011) and Tonttila et al. (2017); hence we do not focus on it here. The well-mixed layer continues to grow throughout the night, until the entire fog layer is well mixed and turbulent by 08:00 UTC.

\section{NWP model improvement}

To test whether improving the representation of aerosol activation would improve the simulation of fog in the NWP model, we make a simple adjustment to the cloud droplet profile used in the UKV (denoted "Drop Taper"). Instead of tapering from a fixed value $\left(75 \mathrm{~cm}^{-3}\right)$ at the surface to the aerosol-dependent value at $150 \mathrm{~m}$, we keep the droplet number fixed throughout the lowest $50 \mathrm{~m}$ of the atmosphere, before tapering towards the aerosol value above this. This is motivated by the observations and LES results, which show 
(a)
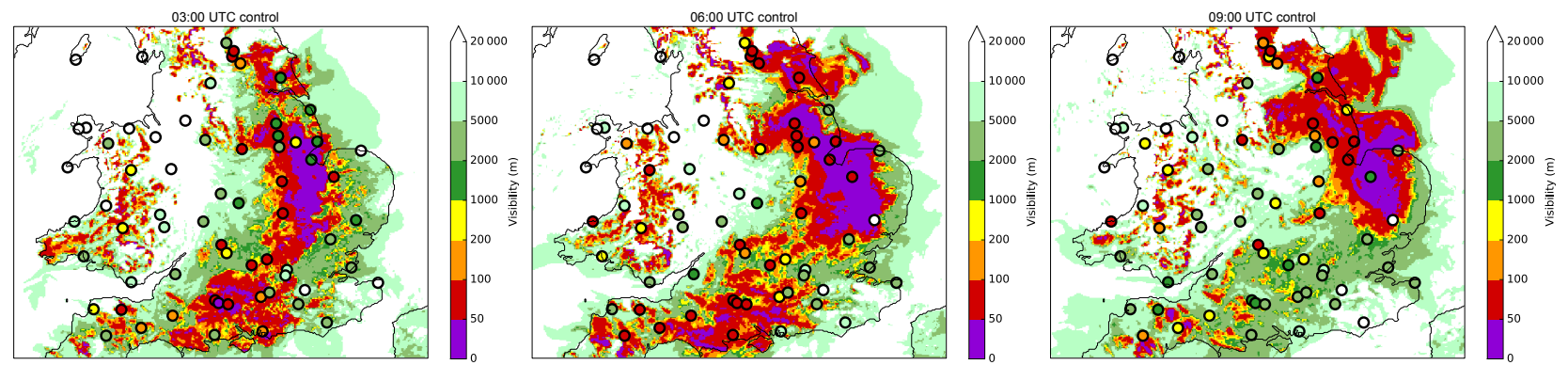

(b)
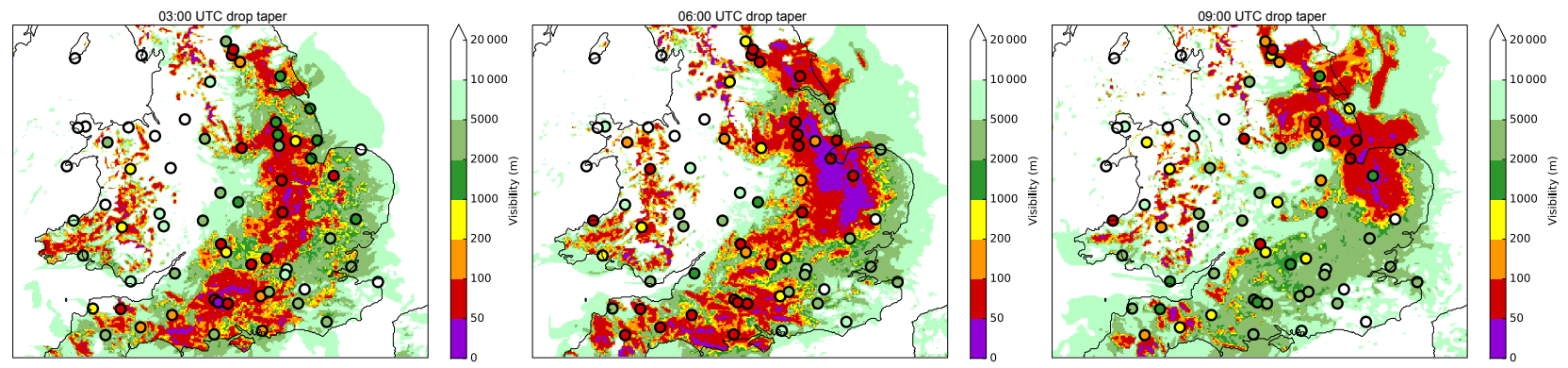

Figure 11. Visibility forecasts from 00:00 UTC on 10 February 2015 at $3 \mathrm{~h}$ intervals from the UKV control (a) and with modified droplet number (b). Filled circles show observations.

that the cloud droplet number is reasonably uniform throughout the fog layer. We also reduce the fixed value used in the lowest $50 \mathrm{~m}$ to $50 \mathrm{~cm}^{-3}$, which is more representative of the observations, although still possibly too high. Clearly this choice is likely to be location and case specific and requires some adjustments for more polluted locations as discussed in Jayakumar et al. (2018). A universal parameterisation would require some link to aerosol.

Figures 1-7 and 10 show the results from this simulation and demonstrate that improvement is possible. The downwelling long-wave radiation (Fig. 6) now remains much lower throughout the night, which allows the surface to remain cool and the sensible heat flux to remain near zero (Fig. 2). The model can maintain a stable atmospheric temperature profile for the early part of the night (Fig. 3a), and eventually it transitions to a well-mixed profile (Fig. 10a). Therefore, it would appear that by having a realistic estimate of cloud droplet numbers in fog we can significantly improve NWP fog simulations.

The mechanisms by which this improvement occur are twofold. Firstly, the reduced cloud droplet number increases the bulk sedimentation rate, which is calculated via Stokes Law (Wilkinson et al., 2013). This increases the rate at which condensed water is removed from the fog layer onto the surface, physically thinning the fog layer, i.e. the LWP is reduced. This is shown in Fig. 4, where the LWP is approximately halved, yet the water deposition rate (which is almost entirely droplet settling) is largely unchanged. Secondly, the increased effective radius, which comes from reducing the cloud droplet number, reduces the cloud absorptivity to upwelling long-wave radiation (Slingo and Schrecker, 1982).
This allows more radiation to be emitted to space, reducing the effectiveness of the fundamental process by which radiation fog develops - long-wave emission from the fog itself (Fig. 6), which is proportional to the absorption. Cooling from the fog top is less efficient at turbulence production, and downwelling long-wave radiation from the fog is less efficient at heating the surface (and thus enabling surface-driven turbulence to form). Both of these processes inhibit the transition to well-mixed fog. The radiatively inactive cloud experiment is an extreme example of this effect.

Given the simple nature of the aerosol representation in the UKV and the current method of calculating cloud droplet numbers from this, the solution proposed above may actually be a suitable candidate for operational NWP implementation over the UK. To evaluate this, we run a month-long trial of the full data assimilation and forecast system for February 2015 with four forecasts per day (00:00, 06:00, 12:00, 18:00 UTC), each $36 \mathrm{~h}$ in length. This represented a typical UK winter, comprising periods of high pressure with calm, potentially foggy conditions, and periods of westerly flow bringing low-pressure frontal systems across the country. The headline result is a small improvement across all measures of forecast skill (wind speed, temperature, cloud cover, precipitation, visibility). One of the more interesting changes was a non-negligible improvement in screen temperature forecasts. Despite the fact that there were only relatively few foggy days during the month, the screen temperature error (similar to Fig. 2a) is so great when fog is present, that improvements to this can be seen in the mean temperature error across the entire month. 
The main improvements, however, are seen in surface visibility forecasts, such as those shown in Fig. 11. The figure shows a widespread fog event over central and southern England on 10 February 2015. The fog onset occurs around 01:00 UTC in the observations, and both forecasts reproduce this reasonably well. However, once the fog is formed in the control simulation, it is instantly thick, well-mixed fog with visibilities $<50 \mathrm{~m}$, symptomatic of the problems discussed in Sect. 3. This is not observed in reality, with many stations reporting visibilities nearer to $100 \mathrm{~m}$. The control simulation maintains these low visibilities throughout the night as the fog moves across the country. By 09:00 UTC, the fog is dissipating in most places in reality, whilst the model retains a large area of thick fog with very low visibility.

With the revised droplet taper, the onset and dissipation phases of the fog event are improved. The fog onset is slower, with visibilities around $100 \mathrm{~m}$ forecast at 03:00 UTC, in general agreement with the observations. By 06:00 UTC, the fog has thickened, becoming well mixed and with visibilities in places falling below $50 \mathrm{~m}$. Whilst this is still too thick compared to the observations, it is certainly much better than the control. By 09:00 UTC, the fog has started to dissipate in the model, with visibilities rising, again in better agreement with the observations.

Figure 12 provides more quantitative support for these conclusions, presenting categorical verification of all forecasts in the trial period against all available surface observations. Following Mason (2003), we define a $2 \times 2$ contingency table such that $a$ is the number of hits, $b$ is the number of false alarms, $c$ is the number of misses and $d$ is the number of correct negatives. We then determine the equitable threat score (ETS) as $(a-X) /(a-X+b+c)$ where $X=(a+b)(a+c) /(a+b+c+d)$, the frequency bias as $(a+b) /(a+c)$, probability of detection (hit rate) as $a /(a+c)$ and the probability of false detection (false alarm rate) as $b /(a+b)$. Perfect scores are 1 for the ETS, frequency bias and probability of detection, and 0 for the probability of false detection. In Fig. 12 we consider the $200 \mathrm{~m}$ threshold for visibility, although results are similar at other thresholds (e.g. $1 \mathrm{~km}$ ). As shown, the control simulation was overforecasting low-visibility events, with a frequency bias $>1$ and a probability of false detection $>0$. Including the modified drop taper has clearly improved both of these metrics. Importantly, it has done this without significantly degrading the probability of detection, which remains largely unchanged, and therefore the ETS is improved. These results are consistent with the main results from IOP1 and the case study from this trial period is presented in Fig. 11. The control simulation produces fog which is too thick, too fast and tends to persist for too long; i.e. it overforecasts. By improving the droplet numbers, this behaviour is improved and can be seen in the statistical analysis.

Therefore, although not a panacea, the changes presented here certainly present a useful improvement in fog modelling and highlight that an accurate representation of aerosol and
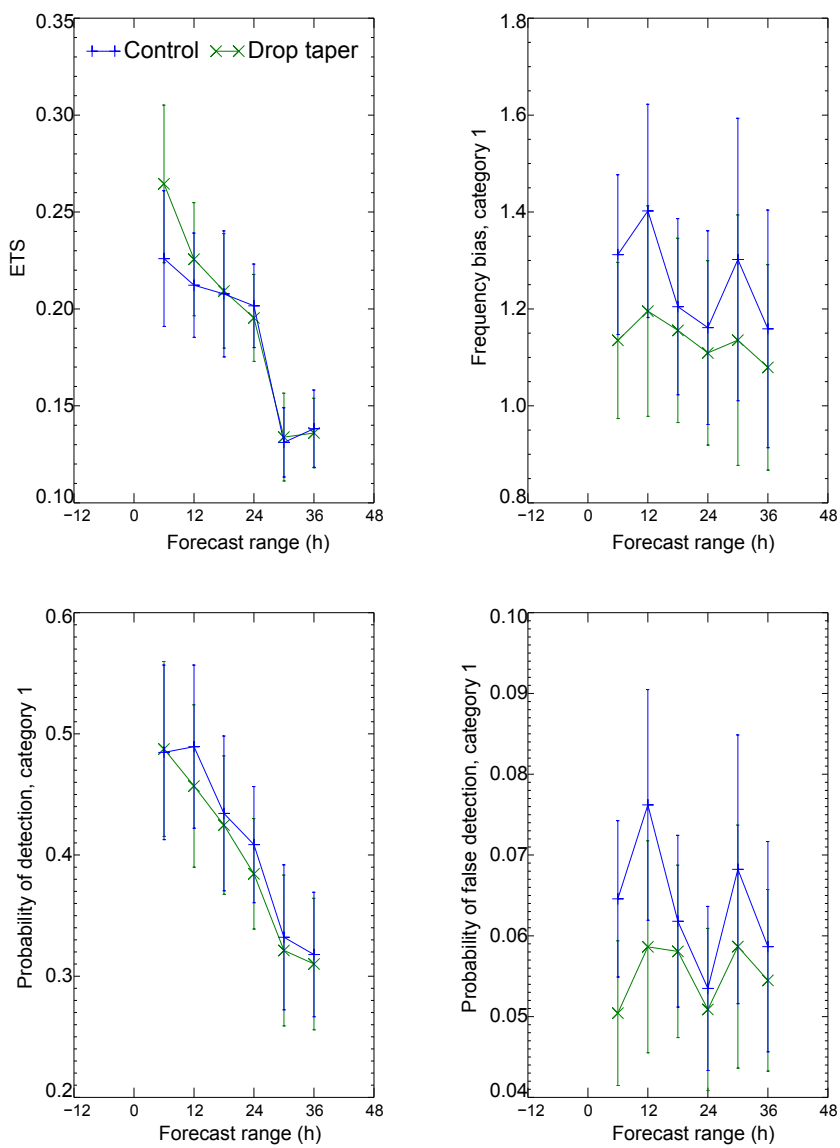

Figure 12. NWP model verification of visibility from 5 February to 5 March 2015 utilising all observations and forecasts (4 per day) over UK land areas. Panels show the equitable threat score (ETS), frequency bias, probability of detection and probability of false detection, for a visibility threshold of $200 \mathrm{~m}$, from the UKV control (blue) and with modified droplet number (green).

its interaction with fog are key challenges for NWP. Future work should look to link the near-surface droplet number to aerosol for a more complete and globally universal solution.

\section{Conclusions}

The manner in which atmospheric aerosol concentrations influence the number and size of fog droplets created in a typical radiation fog event, and how this influences the development of the fog, has been discussed. For given aerosol concentrations, the number of activated droplets is much lower in fog than usually found in clouds, due to the absence of strong updraughts to force cooling of air parcels. Instead, the activation of droplets relies on the very slow radiative cooling of the air, which creates small supersaturations, resulting in relatively few droplets becoming activated. The consequence of this for fog development is that fog can remain optically thin for many hours, relying on the physical growth of the fog 
(a) GA7 (1989-2008)
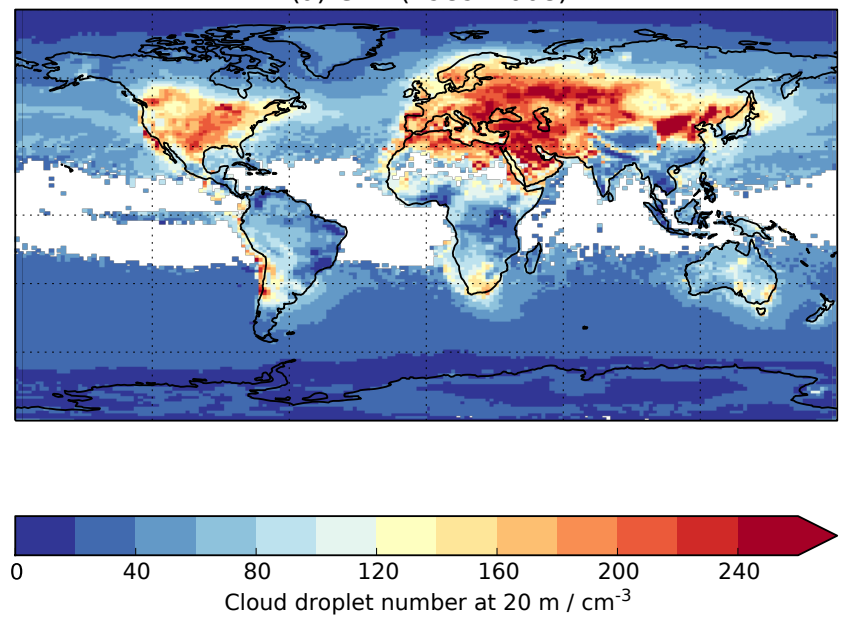

(b) Reduced min - GA7 (1989-2008)
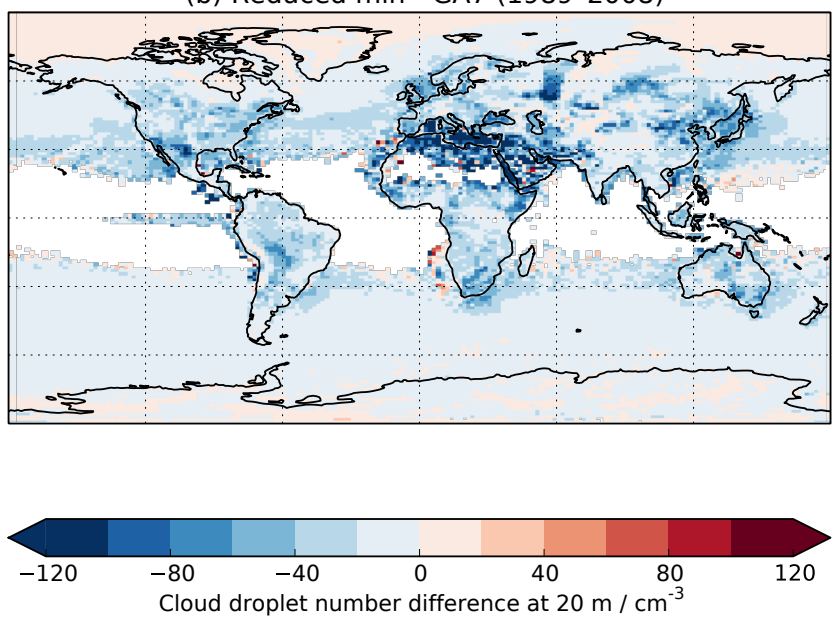

Figure 13. (a) 20-year mean cloud droplet number concentration at the lowest model level (20 m) from an atmosphere only simulation of HadGEM3-GA7. (b) The difference from this when reducing the minimum updraught speed used for aerosol activation from 0.1 to $0.01 \mathrm{~ms}^{-1}$.

layer to increase its optical depth and force the transition to well-mixed fog with a turbulent structure of its own. We can therefore summarise that key factors affecting the development of well-mixed fog include (i) the amount of time available for development before sunrise, i.e. the length of the night and how soon after sunset the first fog forms; (ii) the speed with which the fog layer can deepen, strongly governed by the humidity profile - a moist environment will allow the fog to grow quicker and transition faster; and (iii) the amount of accumulation and coarse-mode aerosol present for activation, as sensitivity tests with the LES demonstrated that considerably increasing the initial concentrations of larger aerosol lead to a faster transition to well-mixed fog. Nonlocal effects and advection are other factors that have not been discussed in this work but are likely to be important.

We have shown that accurate prediction of fog droplet number concentrations is crucially important to the accurate simulation of radiation fog. Excessive number concentrations, and therefore droplets which are too small, too radiatively important and do not sediment out fast enough, quickly lead to the fog becoming optically thick and well mixed, in stark contrast to the observations. This may appear to contradict the results of Maronga and Bosveld (2017), who find little effect on their simulations from changing the droplet number concentration. However, we believe their results are broadly consistent with our own. The simulations presented in Maronga and Bosveld (2017) transition rapidly to wellmixed fog, i.e. within $30 \mathrm{~min}$ of the first onset of fog. Therefore, their simulation is very similar to our control simulation, and their sensitivity studies explore a range of droplet numbers (100-200 $\mathrm{cm}^{-3}$ ) similar to our control simulation. Our observations and LES show droplet numbers much lower than this range $\left(<50 \mathrm{~cm}^{-3}\right)$, and it is only when we reduce the droplet numbers to this value that we achieve a simulation with a slow transition to well-mixed fog. It is also worth noting that the observations on which the Maronga and Bosveld (2017) simulations are based also present a slow transition to well-mixed fog (approximately $5 \mathrm{~h}$ from the first onset), and so it would be interesting rerun their case with a much lower droplet concentration to see if the simulated transition can be improved.

This threshold-type behaviour occurs because once the fog has become optically thick, further changes to the cloud droplet number do little to affect the surface radiation balance and therefore fog development. It is only when the model can simulate fog in an optically thin (i.e. upwelling and downwelling long-wave radiation not in balance) and turbulently stable state, that the droplet number has a greater influence as it can determine when the transition between these states occurs. We believe that these results and suggested model improvements should be applicable to any NWP model, provided that the parameterisations of droplet settling and longwave cloud absorption correctly depend on the droplet number/size and so are keen to conduct an intercomparison of NWP models for a fog case like this to investigate these (and other) sensitivities.

Whilst we have shown that the use of a simple approach to represent low droplet numbers in fog can lead to useful improvements in NWP skill, this work has highlighted a key issue which has been overlooked in many NWP and climate models - how aerosol activation and droplet numbers in fog are calculated. More complex parameterisations of aerosol activation, such as Abdul-Razzak and Ghan (2000), are based around the strength of updraughts. Yet in this paper, we have shown that the minimum updraught speed often used in these parameterisations is considerably larger than those found in 
radiation fog, and the radiative cooling of the atmosphere is not sufficient to account for this discrepancy. Therefore, it is likely that most models using these types of activation parameterisation produce excessive aerosol activation in their lowest model levels.

Poor representation of aerosol activation has notable consequences for climate models and their simulation of the aerosol effective radiative forcing of the climate system (Myhre et al., 2013). Figure 13a shows the in-cloud mean cloud droplet number concentration in the lowest model level of a 20-year present-day climate simulation using the Met Office climate model HadGEM3-GA7 (Walters et al., 2017a). Throughout most of the Northern Hemisphere land masses, when fog is present, the predicted droplet numbers are in excess of $150 \mathrm{~cm}^{-3}$, with peak values over $250 \mathrm{~cm}^{-3}$. This model is typical of many climate models in using the Abdul-Razzak and Ghan (2000) activation parameterisation with a minimum updraught speed of $0.1 \mathrm{~ms}^{-1}$. Based on the results of Sect. 4, Fig. 13b presents a sensitivity test where this minimum value is reduced to $0.01 \mathrm{~ms}^{-1}$. As shown, there is a widespread reduction in the fog droplet number, by up to $50-100 \mathrm{~cm}^{-3}$ in many regions.

Figure 13 demonstrates that an artificial numerical minimum in the aerosol activation code is actually responsible for a large proportion of near-surface aerosol activation in HadGEM3-GA7. There is also potentially a significant impact on the climate system from this process, as the regions where the activation is happening are also predominantly the regions where the aerosol concentrations have grown most significantly throughout the 20th century. To quantify this, we rerun the simulations with pre-industrial aerosol concentrations, allowing us to estimate the effective radiative forcing following the method of Andrews (2014). The results show that reducing the minimum updraught speed reduces (i.e. makes less negative) the aerosol effective radiative forcing by $0.1 \mathrm{~W} \mathrm{~m}^{-2}$. This is not an insignificant change from a process which has been largely unconsidered by climate models to date. Whilst it is beyond the scope of the current paper to evaluate these changes to HadGEM3-GA7 (this will be done in Mulcahy et al., 2018), it is clear that the representation of fog processes in climate models is an area warranting further attention with high priority. Vautard et al. (2009) showed that recent reductions in fog occurrence over Europe are a significant contributor to surface temperature warming, and therefore missing or misrepresenting this process in climate projections is problematic.

Data availability. All data used in this study are available from the authors upon request.

Competing interests. The authors declare that they have no conflict of interest.
Acknowledgements. Ian Boutle and Jeremy Price thank the UK Civil Aviation Authority for providing some funding towards this research. Innocent Kudzotsa, Harri Kokkola and Sami Romakkaniemi are supported by the Academy of Finland (project nos. 283031 and 285068, and the Centre of Excellence in Atmospheric Science, no. 272041). We also thank Adrian Hill for many inspiring discussions on aerosol activation in fog and two reviewers whose comments significantly improved the quality of the manuscript.

Edited by: Yafang Cheng

Reviewed by: Thierry Bergot and one anonymous referee

\section{References}

Abdul-Razzak, H. and Ghan, S. J.: A parameterization of aerosol activation: 2. Multiple aerosol types, J. Geophys. Res., 105, 68376844, https://doi.org/10.1029/1999JD901161, 2000.

Andrews, T.: Using an AGCM to Diagnose Historical Effective Radiative Forcing and Mechanisms of Recent Decadal Climate Change, J. Climate, 27, 1193-1209, https://doi.org/10.1175/JCLI-D-13-00336.1, 2014.

Bergot, T., Escobar, J., and Masson, V.: Effect of small-scale surface heterogeneities and buildings on radiation fog: Large-eddy simulation study at Paris-Charles de Gaulle airport, Q. J. Roy. Meteor. Soc., 141, 285-298, https://doi.org/10.1002/qj.2358, 2015.

Bott, A.: On the influence of the physico-chemical properties of aerosols on the life cycle of radiation fogs, Bound.-Lay. Meteorol., 56, 1-31, https://doi.org/10.1007/BF00119960, 1991.

Boutle, I. A., Abel, S. J., Hill, P. G., and Morcrette, C. J.: Spatial variability of liquid cloud and rain: observations and microphysical effects, Q. J. Roy. Meteor. Soc., 140, 583-594, https://doi.org/10.1002/qj.2140, 2014a.

Boutle, I. A., Eyre, J. E. J., and Lock, A. P.: Seamless Stratocumulus Simulation across the Turbulent Gray Zone, Mon. Weather Rev., 142, 1655-1668, https://doi.org/10.1175/MWRD-13-00229.1, 2014b.

Boutle, I. A., Finnenkoetter, A., Lock, A. P., and Wells, H.: The London Model: forecasting fog at $333 \mathrm{~m}$ resolution, Q. J. Roy. Meteor. Soc., 142, 360-371, https://doi.org/10.1002/qj.2656, 2016.

Clark, P. A., Harcourt, S. A., Macpherson, B., Mathison, C. T., Cusack, S., and Naylor, M.: Prediction of visibility and aerosol within the operational Met Office Unified Model. I: Model formulation and variational assimilation, Q. J. Roy. Meteor. Soc., 134, 1801-1816, https://doi.org/10.1002/qj.318, 2008.

Duynkerke, P. G.: Turbulence, Radiation and fog in Dutch Stable Boundary Layers, Bound.-Lay. Meteorol., 90, 447-477, https://doi.org/10.1023/A:1026441904734, 1999.

Elias, T., Dupont, J.-C., Hammer, E., Hoyle, C. R., Haeffelin, M., Burnet, F., and Jolivet, D.: Enhanced extinction of visible radiation due to hydrated aerosols in mist and fog, Atmos. Chem. Phys., 15, 6605-6623, https://doi.org/10.5194/acp15-6605-2015, 2015.

Ghan, S. J., Leung, L. R., Easter, R. C., and AbdulRazzak, H.: Prediction of cloud droplet number in a general circulation model, J. Geophys. Res., 102, 21777-21794, https://doi.org/10.1029/97JD01810, 1997. 
Gilardoni, S., Massoli, P., Giulianelli, L., Rinaldi, M., Paglione, M., Pollini, F., Lanconelli, C., Poluzzi, V., Carbone, S., Hillamo, R., Russell, L. M., Facchini, M. C., and Fuzzi, S.: Fog scavenging of organic and inorganic aerosol in the Po Valley, Atmos. Chem. Phys., 14, 6967-6981, https://doi.org/10.5194/acp14-6967-2014, 2014.

Guedalia, D. and Bergot, T.: Numerical Forecasting of Radiation Fog. Part II: A Comparison of Model Simulation with Several Observed Fog Events, Mon. Weather Rev., 122, 1231-1246, https://doi.org/10.1175/15200493(1994)122<1231:NFORFP>2.0.CO;2, 1994.

Gultepe, I., Muller, M. D., and Boybeyi, Z.: A New Visibility Parameterization for Warm-Fog Applications in Numerical Weather Prediction Models, J. Appl. Meteorol. Clim., 45, 14691480, https://doi.org/10.1175/JAM2423.1, 2006.

Gultepe, I., Pearson, G., Milbrandt, J. A., Hansen, B., Platnick, S., Taylor, P., Gordon, M., Oakley, J. P., and Cober, S. G.: The Fog Remote Sensing and Modeling Field Project, B. Am. Meteorol. Soc., 90, 341-359, https://doi.org/10.1175/2008BAMS2354.1, 2009.

Hammer, E., Gysel, M., Roberts, G. C., Elias, T., Hofer, J., Hoyle, C. R., Bukowiecki, N., Dupont, J.-C., Burnet, F., Baltensperger, U., and Weingartner, E.: Size-dependent particle activation properties in fog during the ParisFog 2012/13 field campaign, Atmos. Chem. Phys., 14, 10517-10533, https://doi.org/10.5194/acp-1410517-2014, 2014.

Jayakumar, A., Rajagopal, E. N., Boutle, I. A., George, J. P., Mohandas, S., Webster, S., and Aditi, S.: An Operational Fog Prediction System for Delhi using the $330 \mathrm{~m}$ Unified Model, Atmos. Sci. Lett., 19, e796, https://doi.org/10.1002/asl.796, 2018.

Kokkola, H., Korhonen, H., Lehtinen, K. E. J., Makkonen, R., Asmi, A., Järvenoja, S., Anttila, T., Partanen, A.-I., Kulmala, M., Järvinen, H., Laaksonen, A., and Kerminen, V.-M.: SALSA - a Sectional Aerosol module for Large Scale Applications, Atmos. Chem. Phys., 8, 2469-2483, https://doi.org/10.5194/acp-8-24692008, 2008.

Maalick, Z., Kühn, T., Korhonen, H., Kokkola, H., Laaksonen, A., and Romakkaniemi, S.: Effect of aerosol concentration and absorbing aerosol on the radiation fog life cycle, Atmos. Eviron., 133, 26-33, https://doi.org/10.1016/j.atmosenv.2016.03.018, 2016.

Maronga, B. and Bosveld, F.: Key parameters for the life cycle of nocturnal radiation fog: a comprehensive large-eddy simulation study, Q. J. Roy. Meteor. Soc., 143, 2463-2480, https://doi.org/10.1002/qj.3100, 2017.

Mason, I. B.: Binary Events, in: Forecast verification - a practitioner's guide in atmospheric science, edited by: Jolliffe, I. T. and Stephenson, D. B., Wiley, 37-76, 2003.

Mazoyer, M., Lac, C., Thouron, O., Bergot, T., Masson, V., and Musson-Genon, L.: Large eddy simulation of radiation fog: impact of dynamics on the fog life cycle, Atmos. Chem. Phys., 17, 13017-13035, https://doi.org/10.5194/acp-17-13017-2017, 2017.

Morrison, H. and Gettelman, A.: A New Two-Moment Bulk Stratiform Cloud Microphysics Scheme in the Community Atmosphere Model, Version 3 (CAM3). Part I: Description and Numerical Tests, J. Climate, 21, 3642-3659, https://doi.org/10.1175/2008JCLI2105.1, 2008.
Mulcahy, J. P., Jones, C., Sellar, A., Johnson, B., Boutle, I., Jones, A., Andrews, T., Rumbold, S., Mollard, J., Bellouin, N., Johnson, C., Williams, K., Grosvenor, D., and McCoy, D. T.: Improved aerosol processes and effective radiative forcing in HadGEM3 and UKESM1, J. Adv. Model. Earth Syst., in preparation, 2018.

Myhre, G., Shindell, D., Bréon, F.-M., Collins, W., Fuglestvedt, J., Huang, J., Koch, D., Lamarque, J.-F., Lee, D., Mendoza, B., Nakajima, T., Robock, A., Stephens, G., Takemura, T., and Zhang, H.: Anthropogenic and Natural Radiative Forcing, in: Climate Change 2013: The Physical Science Basis, Cambridge University Press, Cambridge, United Kingdom and New York, NY, USA, 2013.

Osborne, S. R., Abel, S. J., Boutle, I. A., and Marenco, F.: Evolution of stratocumulus over land: comparison of ground and aircraft observations with numerical weather prediction simulations, Bound.-Lay. Meteorol., 153, 165-193, https://doi.org/10.1007/s10546-014-9944-0, 2014.

Price, J.: Radiation Fog. Part I: Observations of Stability and Drop Size Distributions, Bound.-Lay. Meteorol., 139, 167-191, https://doi.org/10.1007/s10546-010-9580-2, 2011.

Price, J. D. and Clark, R.: On the Measurement of Dewfall and Fog-Droplet Deposition, Bound.-Lay. Meteorol., 152, 367-393, https://doi.org/10.1007/s10546-014-9930-6, 2014.

Price, J., Lane, S., Boutle, I., Smith, D., Bergot, T., Lac, C., Duconge, L., McGregor, J., Kerr-Munslow, A., Pickering, M., and Clark, R.: LANFEX: a field and modelling study to improve our understanding and forecasting of radiation fog, B. Am. Meteorol. Soc., https://doi.org/10.1175/BAMS-D-16-0299.1, 2018.

Slingo, A. and Schrecker, H. M.: On the shortwave radiative properties of stratiform water clouds, Q. J. Roy. Meteor. Soc., 108, 407-426, https://doi.org/10.1002/qj.49710845607, 1982.

Spracklen, D. V., Carslaw, K. S., Pöschl, U., Rap, A., and Forster, P. M.: Global cloud condensation nuclei influenced by carbonaceous combustion aerosol, Atmos. Chem. Phys., 11, 9067-9087, https://doi.org/10.5194/acp-11-9067-2011, 2011.

Tonttila, J., Maalick, Z., Raatikainen, T., Kokkola, H., Kühn, T., and Romakkaniemi, S.: UCLALES-SALSA v1.0: a largeeddy model with interactive sectional microphysics for aerosol, clouds and precipitation, Geosci. Model Dev., 10, 169-188, https://doi.org/10.5194/gmd-10-169-2017, 2017.

Tudor, M.: Impact of horizontal diffusion, radiation and cloudiness parameterization schemes on fog forecasting in valleys, Meteorol. Atmos. Phys., 108, 57-70, https://doi.org/10.1007/s00703010-0084-x, 2010.

Vautard, R., Yiou, P., and van Oldenborgh, G.-J.: Decline of fog, mist and haze in Europe over the past 30 years, Nat. Geosci., 2, 115-119, https://doi.org/10.1038/ngeo414, 2009.

van der Velde, I. R., Steeneveld, G. J., Wichers Schreur, B. G. J., and Holtslag, A. A. M.: Modeling and Forecasting the Onset and Duration of Severe Radiation Fog under Frost Conditions, Mon. Weather Rev., 138, 4237-4253, https://doi.org/10.1175/2010MWR3427.1, 2010.

Vosper, S., Carter, E., Lean, H., Lock, A., Clark, P., and Webster, S.: High resolution modelling of valley cold pools, Atmos. Sci. Let., 14, 193-199, https://doi.org/10.1002/as12.439, 2013.

Walters, D., Baran, A., Boutle, I., Brooks, M., Earnshaw, P., Edwards, J., Furtado, K., Hill, P., Lock, A., Manners, J., Morcrette, C., Mulcahy, J., Sanchez, C., Smith, C., Stratton, R., Tennant, 
W., Tomassini, L., Van Weverberg, K., Vosper, S., Willett, M., Browse, J., Bushell, A., Dalvi, M., Essery, R., Gedney, N., Hardiman, S., Johnson, B., Johnson, C., Jones, A., Mann, G., Milton, S., Rumbold, H., Sellar, A., Ujiie, M., Whitall, M., Williams, K., and Zerroukat, M.: The Met Office Unified Model Global Atmosphere 7.0/7.1 and JULES Global Land 7.0 configurations, Geosci. Model Dev. Discuss., https://doi.org/10.5194/gmd-2017291, in review, 2017a.

Walters, D., Boutle, I., Brooks, M., Melvin, T., Stratton, R., Vosper, S., Wells, H., Williams, K., Wood, N., Allen, T., Bushell, A., Copsey, D., Earnshaw, P., Edwards, J., Gross, M., Hardiman, S., Harris, C., Heming, J., Klingaman, N., Levine, R., Manners, J., Martin, G., Milton, S., Mittermaier, M., Morcrette, C., Riddick, T., Roberts, M., Sanchez, C., Selwood, P., Stirling, A., Smith, C., Suri, D., Tennant, W., Vidale, P. L., Wilkinson, J., Willett, M., Woolnough, S., and Xavier, P.: The Met Office Unified Model Global Atmosphere 6.0/6.1 and JULES Global Land 6.0/6.1 configurations, Geosci. Model Dev., 10, 14871520, https://doi.org/10.5194/gmd-10-1487-2017, 2017 b.
West, R. E. L., Stier, P., Jones, A., Johnson, C. E., Mann, G. W., Bellouin, N., Partridge, D. G., and Kipling, Z.: The importance of vertical velocity variability for estimates of the indirect aerosol effects, Atmos. Chem. Phys., 14, 6369-6393, https://doi.org/10.5194/acp-14-6369-2014, 2014.

Wilkinson, J. M., Porson, A. N. F., Bornemann, F. J., Weeks, M., Field, P. R., and Lock, A. P.: Improved Microphysical Parametrization of Drizzle and Fog for Operational Forecasting using the Met Office Unified Model, Q. J. Roy. Meteor. Soc., 139, 488-500, https://doi.org/10.1002/qj.1975, 2013.

Wood, N., Staniforth, A., White, A., Allen, T., Diamantakis, M., Gross, M., Melvin, T., Smith, C., Vosper, S., Zerroukat, M., and Thuburn, J.: An inherently mass-conserving semi-implicit semiLagrangian discretisation of the deep-atmosphere global nonhydrostatic equations, Q. J. Roy. Meteor. Soc., 140, 1505-1520, https://doi.org/10.1002/qj.2235, 2014. 